\title{
Parasympathetic denervation of the iris in alcoholics with vagal neuropathy
}

\author{
ETH TAN, DG LAMBIE, RH JOHNSON, EA WHITESIDE \\ From Dean's Research Group, Wellington Clinical School of Medicine, Wellington Hospital, Wellington, \\ New Zealand
}

SUMMARY Parasympathetic innervation of the pupil was studied in 30 alcoholics. Twelve alcoholics had cardiac vagal neuropathy. The resting pupillary diameters in this group were larger, and pupil reponses to methacholine were greater, than in control subjects or alcoholics without vagal neuropathy. These observations imply that lesions in the parasympathetic supply to the pupil may occur in alcoholics with other evidence of autonomic neuropathy involving the parasympathetic system.

Parasympathetic neuropathy involving the vagus nerve was reported in 1974 from neuropathological studies of four alcoholic patients.' We have recently shown' that evidence of vagal neuropathy may also be obtained during life and that this is not uncommon in alcoholic subjects with other evidence of moderate to severe nervous damage. However, a study of the parasympathetic supply to the pupil in alcoholic subjects showed no evidence of denervation, with $8 \%$ each of alcoholics ${ }^{1}$ and control subjects showing pupillary constriction of $1 \mathrm{~mm}$ or greater with methacholine. Patients in that study had relatively mild nervous damage, with only $40 \%$ having peripheral neuropathy and no patients having vagal neuropathy as determined from the heart rate responses to Valsalva's manoeuvre. It remained to be determined whether, in alcoholics with vagal neuropathy, the third cranial nerve may also be affected. This was the purpose of the present study. Parasympathetic denervation of the pupil was tested by measuring the resting pupil diameter and by examining the supersensitivity of the pupil to topical administration of dilute methacholine.

\section{Methods}

Subjects

Thirty abstinent male alcoholics were investigated. They had a mean age of $51.5 \mathrm{yr}$ (range $30-75 \mathrm{yr}$ ) and a mean period of

Address for reprint requests: Prof RH Johnson. Wellington Hospital. Wellington. New Zealand.

Received 30 March 1983 and in revised form 19 July 1983. Accepted 6 August 1983 abstinence of 5.7 weeks (range 1-44 weeks). They had formerly been drinking 100-300 g ethanol daily for 13-60 years. Eighteen healthy control male subjects (age range 20-54 yr) also participated in the study; for comparison of results with those in the alcoholic patients, only those control subjects aged 40 years or over (twelve subjects, mean age $46.6 \mathrm{yr}$ ) were used. None of the alcoholics or controls were receiving any drug treatment for their eyes.

\section{Photographic studies}

A $2 \%$ solution of methacholine in normal saline ("Mecholyl", acetyl- $\beta$-methylcholine) was used for the pupillary test. The solution was freshly prepared monthly by the Wellington Hospital Pharmacy, sterilised by the method of filtration and kept stored at $4^{\circ} \mathrm{C}$. The study was carried out in a photographic studio under standard lighting conditions. The ambient light was kept moderate and constant. A studio flash unit (timing 1/60th second, exposure $f 11.0$ ) was positioned at a far corner of the room. The subject sat behind a head-rest on which he rested his chin to obtain constant and reproducible positions. Photographs were taken of the eyes with a vertical scale (ruled in centimetres) positioned close to and in the plane of the eyes. The camera used was a Nikon F2 $35 \mathrm{~mm}$ single lens reflex camera with a $105 \mathrm{~mm}$ lens. Two drops of $2 \%$ methacholine were instilled in both eyes which then were closed for 30 seconds, during which time a gentle pressure was applied on the lacrimal duct to delay drainage of fluid. Twenty minutes after instillation of the drug. photographs were again taken of the eyes. Enlarged prints of the eyes and the scale were made from the exposures. The pupil diameters (measured in the horizontal plane) were measured blind by three observers using the centimetre scale on the prints, with an accuracy of $\pm 0.1 \mathrm{~mm}$. The three readings for each pupil were averaged. The constriction of a pupil was the difference in the meaned pupil diameters before and after methacholine administration. The two pupillary constriction values obtained for each person were averaged. 
Autonomic function tests

The subjects were assessed for vagal neuropathy by examination of cardiac responses to standing. deep breathing. Valsalva's manoeuvre and atropine administration.

(a) Heart rate response to standing. The R-R intervals at beats 15 and 30 after standing were determined and expressed as the 30:15 ratio. Ratio $>1.03$ was taken as normal.

(b) Valsalva's manoeuvre. The subject forcibly expired through a mouthpiece and tubing attached to an anaeroid manometer. He maintained an expiratory pressure of 40) $\mathrm{mm} \mathrm{Hg}$ for 20 seconds. The ratio of the longest $\mathrm{R}-\mathrm{R}$ interval after manoeuvre to shortest $\mathrm{R}-\mathrm{R}$ interval during manoeuvre was determined. Ratio $\geqslant 1 \cdot 21$ was taken as normal.

(c) Deep Breathing. The subject breathed deeply at 6-8 breaths/min. The difference between mean maximum heart rate during expiration and mean minimum heart rate during inspiration was determined. A difference of $\geqslant 15$ beats $/ \mathrm{min}$ was taken as normal.

(d) Atropine test. $1.8 \mathrm{mg}$ atropine was given intravenously with an interval of $1 \mathrm{~min}$ between successive (). $6 \mathrm{mg}$ doses. A maximum increase in heart rate of $>20$ beats $/ \mathrm{min}$ was taken as normal.

The alcoholic patients were examined for presence of peripheral neuropathy by examining ankle jerks and vibration sense $(128 \mathrm{c} / \mathrm{s})$ at the ankles.

Differences between subject groups were assessed statistically using Wilcoxon's test for two independent samples. Linear regression analysis was used to correlate resting pupil size and age. Significance of relationships was determined using Spearman's rank correlation coefficient. Comparison of linear regression lines was made by analysis of variance and covariance.

\section{Results}

The alcoholic patients were divided into two groups on the basis of the results of the vagal function tests. There were 18 patients who had no significant evidence of vagal neuropathy - these were assigned to group 1. Group 2 consisted of 12 patients with vagal neuropathy, as determined from abnormalities in two or more of the tests of vagal innervation of the heart (heart rate responses to standing, deep breath-

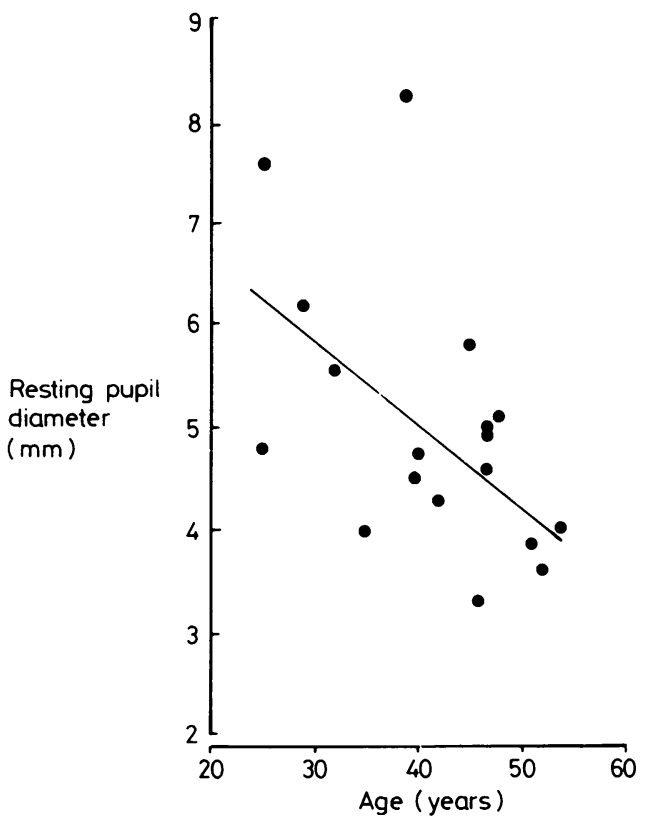

Fig 1 Correlation between resting pupil size and age in 18 normal subjects $(r,=0.64, p<0.05)$.

ing, Valsalva's manoeuvre and atropine). In group 1, 15 of 18 alcoholic patients had evidence of peripheral neuropathy: nine patients had both absent ankle jerks and absent vibration sense at the ankles, four patients had absent vibration sense only and two patients had absent ankle jerks only. In group 2, all patients had both absent ankle jerks and absent vibration sense at the ankles. The results of vagal function tests for the two alcoholic groups and for control subjects aged $\geqslant 40$ years are summarised in the table.

The mean resting pupil diameters of the alcoholic patients with vagal neuropathy were greater than in control subjects or alcoholics without vagal neuro-

Table 1 Comparison of age, resting heart rate, vagal function and pupillary test results in alcoholic patients with (group 1) and without (group 2) vagal neuropathy and in normal controls

\begin{tabular}{|c|c|c|c|c|c|c|c|c|c|}
\hline \multirow[t]{2}{*}{ Subjects } & & \multirow{2}{*}{$\begin{array}{l}\text { Age } \\
\text { (yrs) }\end{array}$} & \multirow{2}{*}{$\begin{array}{l}\text { Resting } \\
\text { heart rate } \\
\text { (beats/min) }\end{array}$} & \multicolumn{4}{|c|}{ Abnormality in vagal function tests } & \multirow{2}{*}{$\begin{array}{l}\text { Mean } \\
\text { resting } \\
\text { pupil } \\
\text { diameter } \\
(\mathrm{mm})\end{array}$} & \multirow{2}{*}{$\begin{array}{l}\text { Pupil } \\
\text { constriction } \\
\text { to } \\
\text { methacholine } \\
(\mathrm{mm})\end{array}$} \\
\hline & & & & $\begin{array}{l}30: 15 \\
\text { ratio }\end{array}$ & $\begin{array}{l}\text { Valsaliat } \\
\text { ratio }\end{array}$ & $\begin{array}{l}\text { Deep } \\
\text { breathing } \\
\text { (beats/min) }\end{array}$ & $\begin{array}{l}\text { Atropine } \\
\text { (beats/min) }\end{array}$ & & \\
\hline $\begin{array}{l}\text { Alcoholic } \\
\text { Group } 1 \\
(n=\mid 8)\end{array}$ & $\begin{array}{l}\text { Mean } \\
\pm \mathrm{SD}\end{array}$ & $\begin{array}{l}49 \cdot 4 \\
\pm 9.2\end{array}$ & $\begin{array}{l}74 \cdot 3 \\
\pm 11 \cdot(1\end{array}$ & $\begin{array}{l}1 \cdot(19) \\
\pm 0 .(199\end{array}$ & $\begin{array}{l}1.50 \\
\pm 0.28\end{array}$ & $\begin{array}{l}19 \cdot 11 \\
\pm 7.65\end{array}$ & $\begin{array}{l}33.44 \\
\pm 12 .(0)\end{array}$ & $\begin{array}{l}4 \cdot 05 \\
\pm 0.64\end{array}$ & $\begin{array}{l}0.17 \\
\pm 0.14\end{array}$ \\
\hline $\begin{array}{l}\text { Alcoholic } \\
\text { Group } 2 \\
(n=12)\end{array}$ & $\begin{array}{l}\text { Mean } \\
\pm \mathrm{SD}\end{array}$ & $\begin{array}{l}54 \cdot 7 \\
\pm 9 \cdot(1\end{array}$ & $\begin{array}{l}92 \cdot 2 \\
\pm 11\end{array}$ & $\begin{array}{l}0.96 \\
\pm 0 .(19\end{array}$ & $\begin{array}{l}1 \cdot 13 \\
\pm 0 .(109\end{array}$ & $\begin{array}{l}8.83 \\
\pm 5.20\end{array}$ & $\begin{array}{l}13.82 \\
\pm 3.71\end{array}$ & $\begin{array}{l}4.95 \\
\pm 0.97\end{array}$ & $\begin{array}{l}0.42 \\
\pm 0.33\end{array}$ \\
\hline $\begin{array}{l}\text { Normal } \\
\text { Subjects } \\
(\mathrm{n}=12)\end{array}$ & $\begin{array}{l}\text { Mean } \\
\pm S D\end{array}$ & $\begin{array}{l}46 \cdot 6 \\
\pm 4 \cdot 4\end{array}$ & $\begin{array}{l}7() \cdot 6 \\
\pm+.7\end{array}$ & $\begin{array}{l}1 \cdot 18 \\
\pm 0 \cdot(16\end{array}$ & $\begin{array}{l}1.76 \\
\pm 0.18\end{array}$ & $\begin{array}{l}28.56 \\
\pm 5.96\end{array}$ & $\begin{array}{l}39 \cdot(10 \\
\pm 3.39\end{array}$ & $\begin{array}{l}4.49 \\
\pm 0.70\end{array}$ & $\begin{array}{l}0 \cdot 16 \\
\pm 0 \cdot 20\end{array}$ \\
\hline
\end{tabular}


pathy (table) and this reached significance $(\mathrm{p}<0.01)$ in the latter case. There were negative correlations between age and resting pupil diameter in all groups of subjects (figs 1.2) and this reached significance for control subjects $(p<0.05)$ and for alcoholics without

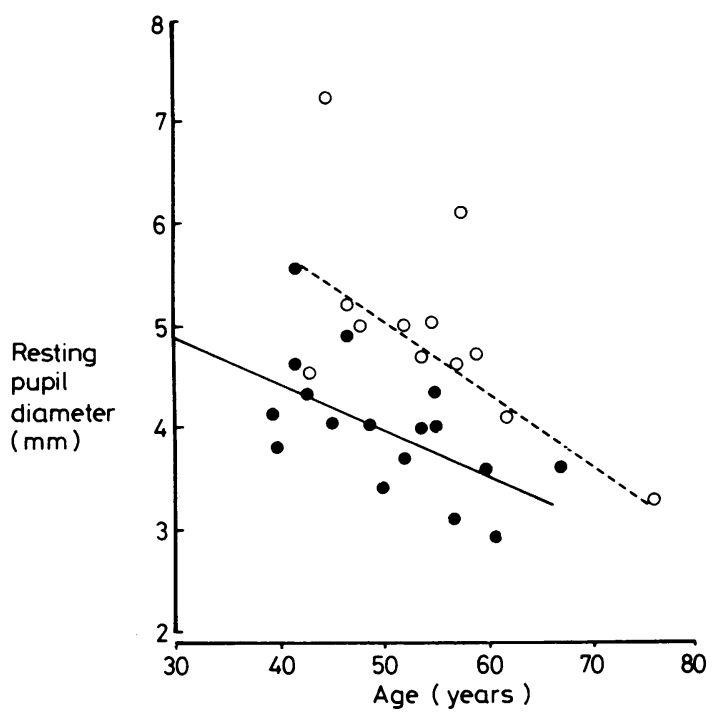

Fig 2 Correlation between resting pupil size and age in the alcoholics: Group 1, filled circles and solid line $\left(r_{s}=0 \cdot 64\right.$, $p<0.005)$. Group 2, open circles and dashed line $\left(r_{s}=0.61, p>0.01\right)$.

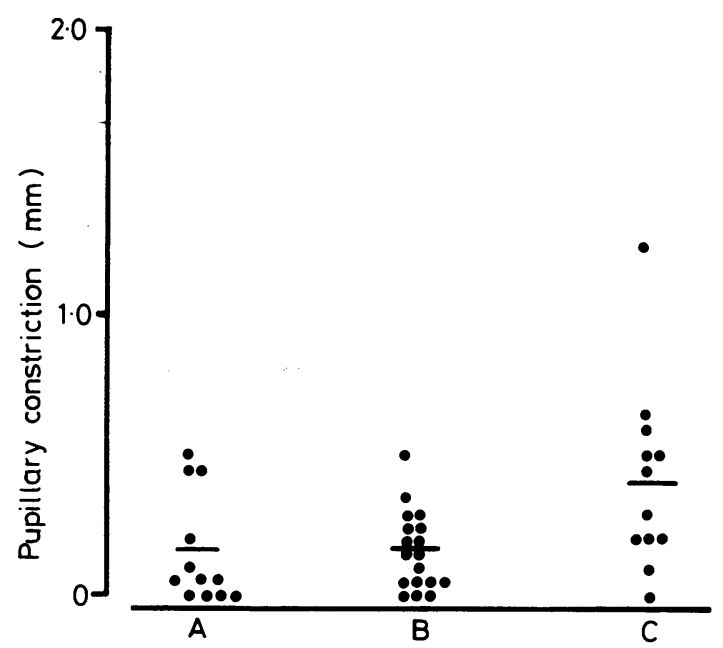

Fig 3 Pupillary constriction after 2\% methacholine. Anormal controls. $B$-alcoholics without vagal neuropathy. $C$-alcoholics with vagal neuropathy. Horizontal bars indicate mean values. Responses in alcoholics with vagal neuropathy were significantly greater than in normal controls $(p<0.05)$ or in alcoholics without vagal neuropathy $(p=0.05)$. vagal neuropathy $(\mathrm{p}<0 \cdot(005)$. This decrease in pupil size with age is well recognised and is due to a decrease in sympathetic tone. ${ }^{4}$ The regression lines of the two groups of alcoholics were significantly different $(\mathrm{p}<0 \cdot 001)$ in position.

Group 1 and group 2 alcoholics had mean pupil constriction to methacholine of $0.17 \mathrm{~mm}$ and 0.42 $\mathrm{mm}$ respectively (fig 3 ). These mean values were significantly different $(p=0.05)$. The control group had a mean pupil constriction of $0 \cdot 16 \mathrm{~mm}$, which was not significantly different from that of group 1 alcoholics but was significantly different $(p<0.05)$ from that of group 2 . No correlations were apparent between age and response to methacholine for any subject group.

\section{Discussion}

The method of photography as used in this study allowed accurate and sensitive measurement of pupil diameters. The resting pupil diameters in alcoholics with vagal neuropathy were larger than in other alcoholic subjects and this was particularly evident when age-related changes in pupil diameter were taken into account. This suggests that alcoholics with vagal neuropathy may also show third nerve lesions; sympathetic activity would be predominant in the pupils of these alcoholics. " This was supported by results of the methacholine test. The responses of the pupils to methacholine were greater in alcoholics with vagal neuropathy than in other alcoholic patients or in control subjects, indicating that the constrictor muscles of the pupils in the former had become supersensitive to acetylcholine, of which methacholine is an analogue.

In a previous study of pupillary responses to methacholine in alcoholic subjects, pupil diameter was measured directly using a transparent plastic ruler. ${ }^{3}$ Accuracy of measurement was limited to the nearest $0.5 \mathrm{~mm}$. Only three alcoholics out of forty showed a supersensitive response to methacholine, as determined from obvious pupillary constrictions of $1 \mathrm{~mm}$ or more. In the present study only one alcoholic subject showed a constriction response of greater than $1 \mathrm{~mm}$, but in view of the significantly increased constriction responses in the alcoholics with vagal neuropathy, as compared to other alcoholics or control subjects, it was clear that third nerve lesions were present in these patients and this was expressed in a relatively moderate supersensitivity to methacholine.

Resting pupil diameter was more clearly different in the two alcoholic patient groups, particularly if the age-related decline in diameter was taken into consideration, than the response to methacholine. For example a 58-year-old subject with vagal neuro- 
pathy showed markedly increased resting pupil diameter $(6 \cdot 1 \mathrm{~mm})$ but there was no constriction response to methacholine. Pupillary dilatation without supersensitivity to methacholine might be explained by a preganglionic rather than postganglionic lesion. A study in animals showed no significant responses to dilute methacholine with preganglionic as opposed to post ganglionic lesions.' A recent study to compare patients with postganglionic (Adie's syndrome) and preganglionic third nerve lesions found no difference in response to methacholine. ${ }^{x}$ However denervation in these patients was presumably more complete than in patients in the present study. With incomplete lesions, it seems likely that supersensitivity would be more marked if these were in postganglionic rather than in preganglionic fibres. We tentatively suggest that the pupillary abnormalities that we have observed in alcoholic subjects are principally due to preganglionic lesions in the third cranial nerve.

In conclusion this study shows that, in chronic alcoholics with neuropathy involving the vagal innervation of the heart, lesions in the parasympathetic supply to the pupil may also occur. This causes moderate pupillary dilatation at rest and in some patients results in supersensitivity to methacholine.

This work was supported by the Alcoholic Liquor Advisory Council of New Zealand and the Medical
Research Council of New Zealand. The authors are grateful to all the subjects who participated.

\section{References}

${ }^{1}$ Novak DJ. Victor M. The vagus and sympathetic nerves in alcoholic polyneuropathy. Arch Neurol 1974;30:27384.

' Duncan G. Johnson RH, Lambie DG, Whiteside EA. Evidence of vagal neuropathy in chronic alcoholics. Lancet 198();ii:1053-7.

${ }^{3}$ Myers W. Willis K, Reeves A. Absence of parasympathetic denervation of the iris in alcoholics. J Neurol Neurosurg Psychiatry 1979;42:1018-9.

${ }^{+}$Korczyn AD, Laor N, Nemet P. Sympathetic pupillary tone in old age. Arch Ophthalmol 1976;94:1905-6.

'Johnson RH, Spalding JMK. The Eyes. Chapter 11 in Disorders of the Autonomic Nervous System. Oxford: Blackwell, 1974:199-219.

6 Johnson RH. Autonomic failure and the eye. In: Bannister R, ed. Autonomic Failure. Oxford: University Press, 1983:508-42.

${ }^{7}$ Adler FH, Scheie $\mathrm{HG}$. The site of disturbance in tonic pupils. Trans Am Ophthalmol Soc 1940;38:183-92.

${ }^{x}$ Ponsford JR, Bannister R, Paul EA. Metacholine pupillary responses in third nerve palsy and Adie's syndrome. Brain 1982;105:583-97. 